\title{
The circulation of the Persian Gulf: a numerical study
}

\author{
J. Kämpf ${ }^{1}$ and M. Sadrinasab ${ }^{2}$ \\ ${ }^{1}$ School of Chemistry, Physics and Earth Sciences, Flinders Research Centre for Coast and Catchment Environments, Flinders \\ University, Adelaide, Australia \\ ${ }^{2}$ Khorramshahr University of Nautical Sciences \& Technology, Khorramshahr, Iran
}

Received: 4 March 2005 - Published in Ocean Sci. Discuss.: 12 May 2005

Revised: 20 April 2006 - Accepted: 30 May 2006 - Published: 5 July 2006

\begin{abstract}
We employ a three-dimensional hydrodynamic model (COHERENS) in a fully prognostic mode to study the circulation and water mass properties of the Persian Gulf - a large inverse estuary. Our findings, which are in good agreement with observational evidence, suggest that the Persian Gulf experiences a distinct seasonal cycle in which a gulfwide cyclonic overturning circulation establishes in spring and summer, but this disintegrates into mesoscale eddies in autumn and winter. Establishment of the gulf-wide circulation coincides with establishment of thermal stratification and strengthening of the baroclinic exchange circulation through the Strait of Hormuz. Winter cooling of extreme saline ( $>45)$ water in shallow regions along the coast of United Arab Emirates is a major driver of this baroclinic circulation.
\end{abstract}

\section{Introduction}

The Persian Gulf, referred to in some local countries as the Arabian Gulf, is an important military, economic and political region owing to its oil and gas resources and is one of the busiest waterways in the world. Countries bordering the Persian Gulf are the United Arab Emirates, Saudi Arabia, Qatar, Bahrain, Kuwait and Iraq on one side and Iran on the other side (Fig. 1).

The Persian Gulf is $\sim 990 \mathrm{~km}$ long and has a maximum width of $370 \mathrm{~km}$. The average depth of the Gulf is $36 \mathrm{~m}$. The Persian Gulf occupies a surface area of $\sim 239000 \mathrm{~km}^{2}$ (Emery, 1956). Extensive shallow regions, $<20 \mathrm{~m}$ deep, are found along the coast of United Arab Emirates (hereafter referred to as Southern Shallows), around Bahrain, and at the head of the Gulf. Deeper portions, $>40 \mathrm{~m}$ deep, are found along the Iranian coast continuing into the Strait of Hormuz,

Correspondence to: J. Kämpf

(jochen.kaempf@flinders.edu.au) which has a width of $\sim 56 \mathrm{~km}$ and connects the Persian Gulf via the Gulf of Oman with the northern Indian Ocean.

Tectonic driven subsidence deepened the seafloor of the Strait on its southern side $(200-300 \mathrm{~m}$ depths are seen in some localised seafloor depressions) and produced a 70 $95 \mathrm{~m}$ deep trough along the Iranian side of the eastern part of the Gulf. A southward widening channel leads from the Strait south across a series of sills (water depth of $\sim 110 \mathrm{~m}$ ) and shallow basins to the shelf edge (Seibold and Ulrich, 1970). The narrow Strait of Hormuz restricts water exchange between the Persian Gulf with the northern Indian Ocean.

The Persian Gulf is a semi-enclosed, marginal sea that is exposed to arid, sub-tropical climate. It is located between latitudes $24^{\circ}-30^{\circ} \mathrm{N}$, and is surrounded by most of the Earth's deserts. The most known weather phenomenon in the Persian Gulf is the Shamal, a northwesterly wind which occurs year round (Perrone, 1981). In winter, the Shamal is of intermittent nature associated with the passage of synoptic weather systems, but it seldom exceeds a speed of $10 \mathrm{~m} / \mathrm{s}$. The summer Shamal is of continuous nature from early June through to July. Seasonal variations of the Shamal are associated with the relative strengths of the Indian and Arabian thermal lows (Emery, 1956).

The Gulf experiences evaporation rates of $\sim 2 \mathrm{~m} / \mathrm{yr}$ (per unit surface area) (Privett, 1959; Hastenrath and Lamb, 1979; Meshal and Hassan, 1986; Ahmad and Sultan, 1990) that exceed by far the net freshwater input by precipitation $(\sim 0.15 \mathrm{~m} / \mathrm{yr})$ (Johns et al., 2003$)$ and river discharge. The major river source in the Persian Gulf is the Shatt-Al-Arab (called Arvand Roud by some countries), being located at the head of the Gulf and being fed by the Euphrates, Tigris and Karun rivers.

Previous estimates of the annual-mean discharge of the Shatt-Al-Arab vary from $35 \mathrm{~km}^{3} / \mathrm{yr}$ (Saad, 1978; Johns et al., 2003), being equivalent to $0.15 \mathrm{~m} / \mathrm{yr}$ when being evenly distributed over the surface of the gulf, to $\sim 45 \mathrm{~km}^{3} / \mathrm{yr}$ $(0.19 \mathrm{~m} / \mathrm{yr})$ (Wright, 1974; Reynolds, 1992). These values are likely an overestimate of current river discharge that has

Published by Copernicus GmbH on behalf of the European Geosciences Union. 


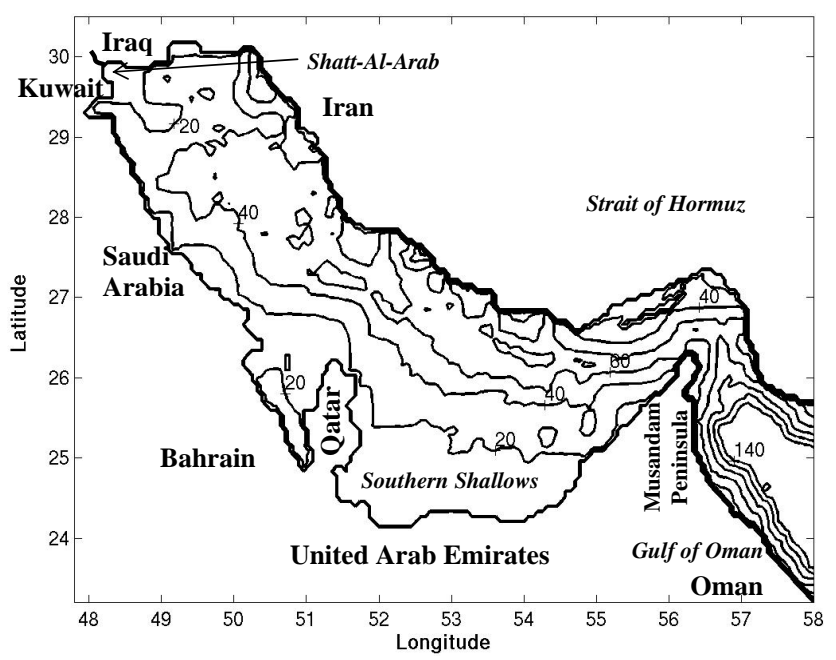

Fig. 1. Bathymetry $(\mathrm{CI}=20 \mathrm{~m})$ used in this study.

been reduced to an unknown extent by dam constructions, such as the Atatürk dam built in the Euphrates by Turkey in 1990 and other dams and reservoirs built by Iran, Iraq, and Syria.

The U.S. Naval Oceanographic Office (Alessi et al., 1999) has archived historical temperature-salinity observations in the Persian Gulf. This data consists of a number of 1597 temperature-salinity profiles, including Mt. Mitchell data (Reynolds, 1993), and spans observations over 73 years from 1923 to 1996. The Mt. Mitchell expedition comprised 500 CTD casts taken in the Persian Gulf, the Strait of Hormuz and the Gulf of Oman over a period of 3.5 months (26 February12 June 1992) (Reynolds, 1993). No autumn field data are available for the Gulf. Data coverage in the Southern Shallows and around Bahrain is poor. Alessi et al. (1999) present this data in the form of temperature-salinity-season diagrams that we use for model validation and interpretation of findings. Swift and Bower (2003) (henceforth SB2003) analyse and discuss this data in detail.

Owing to excess evaporation, the Persian Gulf exhibits a reverse estuarine circulation in which, due to geostrophy, the dense bottom outflow follows the coastline of United Arab Emirates, whereas inflow of Indian Ocean Surface Water (IOSW) follows the Iranian coastline (Sugden, 1963; Hunter, 1982; Chao et al., 1992; Reynolds, 1993; Johns et al., 2003; SB2003). Reynolds (1993) and others (e.g. Hunter, 1983) proposed that the densest water driving this bottom outflow formed in the Southern Shallows. Contrary to this, on the basis of an axial transect, SB2003 argued that the densest water formed near the head of the Gulf and suggested that water masses of the Southern Shallows were too warm in winter and thus not dense enough to drive the bottom outflow. This conclusion, however, might be biased by the location of this transect which does not include the Southern Shallows (see Fig. 7a in SB2003). Winter transects reaching into the
Southern Shallows (see Figs. 8a-b in SB2003), however, reveal high densities $\left(>1030 \mathrm{~kg} \mathrm{~m}^{-3}\right)$ in this region exceeding values observed near the head. Also indicated are local injections of this dense water into the main outflow, seen as a local salinity and density maximum in the axial section in vicinity of the Southern Shallows (see Fig. 7a in SB2003). Therefore, the authors deem the conclusion of SB2003, stating that the densest water forms at the Gulf's head, elusory.

Direct observations of the circulation within the Persian Gulf are scarce. Ship-drift records indicate northwestward flow of speeds $>10 \mathrm{~cm} / \mathrm{s}$ along the Iranian coast to a change in trend of the coast near $51.5^{\circ} \mathrm{E}$ and southwestward flow in the southern Gulf away from Iran (Hunter, 1983; Chao et al., 1992). Findings from vector-averaging current meters and drifter buoys, deployed during the Mt. Mitchell cruises, partially agree with the historic ship drift data. There are occasions of disagreement where the northwestward coastal flow weakened to speeds $<3 \mathrm{~cm} / \mathrm{s}$ near the surface, presumably due to the presence of strong north-westerly winds during the time of measurement (SB2003).

The salinity distribution in the Persian Gulf experiences significant seasonal variations. For unknown reasons, the inflow of IOSW strengthens in late spring and summer and moves further up the Iranian coastline and closer to the coast of United Arab Emirates (Reynolds, 1993; SB2003). This leads to formation of a pronounced summer salinity front in the Persian Gulf with the 39-salinity contour following largely the 40-m depth contour (see Reynolds, 1993). Salinity varies across the front by 2 over a distance of $50-100 \mathrm{~km}$. SB2003 suggested that this front represent a region of mixing between water masses and not a boundary between flows moving in different directions. In winter, the front retreats toward the Strait of Hormuz by $\sim 200 \mathrm{~km}$ (see SB2003). As a result of this, surface Gulf waters are saltier in winter than in summer, which has puzzled physical oceanographers for many decades. Schott (1908) attributed the difference to changing river fluxes. Emery (1956) attributed this feature to seasonal changes in evaporation rates. Chao et al. (1992) suggested that wind stress hindered the inflow of IOSW into the Persian Gulf during winter. On the basis of initial findings of Johns and Olson (1998), SB2003 argued that the dense outflow be steady and therefore be not correlated to variations of the influx of IOSW. Instead of this, they proposed that variable influx of IOSW be driven by seasonally variable evaporative lowering of sea surface height. We were not fully satisfied with either of these interpretations as these did not account for mixing processes in the water column that might remove surface salinity extremes.

From the analysis of upward-looking ADCP measurements in the Strait of Hormuz, taken over the period December 1996 to March 1998, the volume transport of the dense bottom outflow through the Strait has been estimated at $0.15 \pm 0.03 \mathrm{~Sv}\left(1 \mathrm{~Sv}=10^{6} \mathrm{~m}^{3}\right)$ (Johns et al., 2003). This outflow removes a water volume equivalent to the total volume of the Persian Gulf in $<2$ years. The magnitude of this 
outflow, carrying a layer-averaged salinity of 39.5 , varies by $\pm 20 \%$ seasonally and appears to be strongest in late spring and summer (see Johns et al., 2003) in conjunction with peak inflow IOSW into the Gulf. Thus, there appears to be a correlation between the strength of the bottom outflow and that of the IOSW inflow, which conflicts with SB2003, who claim that the magnitude of the bottom outflow should peak in winter.

Observational evidence suggests the existence of a coastal upwelling jet that flows southeastward along the northern Iranian coast to at least $28^{\circ} \mathrm{N}$ (see Reynolds, 1993). There is sedimentological evidence that this current is a long-term feature that significantly affects sediment transport in the northern Gulf (Uchupi et al., 1996).

Tides in the Persian Gulf are complex and the dominant pattern varies from being primarily semi-diurnal to diurnal (Reynolds, 1993). Major semi-diurnal and diurnal tidal constituents in the Persian Gulf are $\mathrm{M}_{2}, \mathrm{~S}_{2}, \mathrm{~K}_{1}$, and $\mathrm{O}_{1}$ (Najafi, 1997). Semi-diurnal constituents have two amphidromic points that sit in the north-western and southern ends of the Gulf, respectively. The diurnal constituents have a single amphidromic point in the centre of the Gulf near Bahrain (Hunter, 1982). Tidal hydrodynamic simulations (e.g. Najafi, 1997) predict tidal flows of $\sim 0.9 \mathrm{~m} / \mathrm{s}$ near the Strait of Hormuz and at the head of the Gulf, and $0.3-0.6 \mathrm{~m} / \mathrm{s}$ elsewhere in the Gulf.

Chao et al. (1992) studied the circulation of the Persian Gulf with a three-dimensional hydrodynamic model under realistic meteorologic forcing. Model predictions indicate that inflow through the Strait peaks at $0.17 \mathrm{~Sv}$ in March and decrease to $0.03 \mathrm{~Sv}$ in August-September, the latter being far too weak as compared with ADCP data (Johns et al., 2003). Chao et al. (2003) were able to simulate the cyclonic overturning circulation in the Gulf, but their simulations had some shortcomings. Firstly, the lateral grid spacing used $(\sim 20 \mathrm{~km})$ did not resolve the internal deformation radius $(\sim 20 \mathrm{~km})$, so that mesoscale instabilities could not adequate be described. Secondly, the total simulation time was limited to 2 years, which may not have been sufficiently long for the model to approach of steady seasonal cycle.

This paper focuses on several aspects of the circulation in the Persian Gulf that have not been comprehensively addressed before. Where are the source regions of dense water formation that drive the outflow through the Strait of Hormuz? Which factors control the seasonally variable exchange circulation through the Strait? Which processes make the Persian Gulf saltier in winter compared to summer? What are the patterns of circulation and water mass properties in autumn where field data are lacking?

To answer these questions, we employ an eddy-resolving, three-dimensional numerical model under realistic climatologic forcing and accurate bottom topography. This model differs from the model application by Chao et al. (1992) in that the spatial grid spacing is much finer $(\sim 7 \mathrm{~km})$, which improves the spatial resolution of mesoscale instabilities, and that total simulation times are much longer (20 years), so that the last years of prediction are uninfluenced by initial conditions. It is noticeable that Sadrinasab and Kämpf (2004) employed a similar model configuration to derive flushing times in the Persian Gulf.

This paper is organised as follows. Section 2 describes the model and the design of experiments. Section 3 discusses the model findings. Section 4 presents conclusions and recommendations for future studies.

\section{Model}

\subsection{Governing equations}

We employ the hydrodynamic part of COHERENS (COupled Hydrodynamical Ecological model for REgioNal Shelf seas) (Luyten et al., 1999) which is based on a bottomfollowing vertical sigma coordinate. The model is run in a fully prognostic mode with Cartesian lateral coordinates on the f plane, using a geographical latitude of $27^{\circ} \mathrm{N}$. The model is based on hydrostatic versions of the Navier-Stokes equations that embrace conservation equations for momentum, volume, heat and salt. The Boussinesq approximation is included in the horizontal momentum equations. The sea surface can move freely; that is, barotropic shallow water motions such as those associated with surface gravity waves are included. The equation of state as defined by the Joint Panel on Oceanographic Tables and Standards (UNESCO, 1981) has been used, wherein pressure effects on density are ignored. See Luyten et al. (1999) for details on hydrodynamic equations and their formulation in sigma coordinates.

\subsection{Model domain and grid resolution}

We employ 5 sigma levels and Cartesian lateral grid spacings of $\Delta x=7.4 \mathrm{~km}$ (east-west direction) and $\Delta y=6.6 \mathrm{~km}$ (north-south direction). Bathymetry and coastline locations are based on ETOPO-2 data that has been interpolated and slightly smoothed onto a 4-min grid (see Fig. 1). This removed local topographic irregularities, often a cause for numerical instabilities, in particular in the Strait of Hormuz. Minimum water depth is chosen at $5 \mathrm{~m}$ and maximum water depth is restricted to $140 \mathrm{~m}$, which applies only to the Gulf of Oman and has no significant impact on the results. Note that restriction to 5 sigma levels is a compromise to maximise model efficiency with relatively fine lateral resolution and long simulation times ( $\sim 20$ years). Shorter simulations with 10 sigma levels yielded similar results (not shown).

\subsection{Initial and boundary conditions}

The model is initialised in winter when vertical stratification is weak throughout the Gulf using uniform temperature and salinity fields with values of $20^{\circ} \mathrm{C}$ and 38 , respectively, which is reasonably close to observational evidence 
Table 1. Climatological data used in model simulations.

\begin{tabular}{llllllll}
\hline Month & $\begin{array}{l}\text { Wind-u } \\
(\mathrm{m} / \mathrm{s})\end{array}$ & $\begin{array}{l}\text { Wind-v } \\
(\mathrm{m} / \mathrm{s})\end{array}$ & $\begin{array}{l}\text { Wind Speed } \\
(\mathrm{m} / \mathrm{s})\end{array}$ & $\begin{array}{l}\text { Air Temperature } \\
\left({ }^{\circ} \mathrm{C}\right)\end{array}$ & $\begin{array}{l}\text { Relative } \\
\text { Humidity }(\%)\end{array}$ & $\begin{array}{l}\text { Precipitation } \\
(\mathrm{mm} / \mathrm{month})\end{array}$ & $\begin{array}{l}\text { Cloudiness } \\
(\%)\end{array}$ \\
\hline $\mathrm{J}$ & 1.82 & -2.98 & 3.49 & 14.91 & 66 & 42 & 34 \\
$\mathrm{~F}$ & 1.75 & -3.125 & 3.58 & 16.29 & 57 & 31 & 22 \\
$\mathrm{M}$ & 1.86 & -3.86 & 4.28 & 19.92 & 46 & 20 & 16 \\
$\mathrm{~A}$ & 1.89 & -4.82 & 5.18 & 24.11 & 35 & 10 & 10 \\
$\mathrm{M}$ & 1.94 & -5.47 & 5.80 & 28.78 & 25 & 0 & 8 \\
$\mathrm{~J}$ & 2.03 & -4.87 & 5.28 & 31.04 & 22 & 0 & 10 \\
$\mathrm{~J}$ & 1.4 & -4.5 & 4.71 & 32.85 & 24 & 0 & 10 \\
$\mathrm{~A}$ & 1.37 & -4.21 & 4.43 & 31.77 & 26 & 0 & 8 \\
$\mathrm{~S}$ & 1.23 & -3.55 & 3.76 & 29.77 & 31 & 0 & 4 \\
$\mathrm{O}$ & 1.51 & -3.12 & 3.47 & 27.14 & 41 & 14 & 7 \\
$\mathrm{~N}$ & 1.88 & -2.9 & 3.46 & 21.48 & 55 & 20 & 20 \\
$\mathrm{D}$ & 2.5 & -2.94 & 3.86 & 17.07 & 64 & 27 & 26 \\
\hline
\end{tabular}

(see Alessi et al., 1999). The model is forced by climatologic monthly mean atmospheric forcing (wind speed, air temperature, humidity, cloud cover and precipitation) at 10-m reference height above ground derived from 54 years (19482002) of NOAA data (Table 1).

The shortwave radiative flux is calculated on an hourly basis to resolve its diurnal variation. Atmospheric conditions are assumed to be uniform in space but variable in time. A quadratic bulk formula is used to calculate surface frictional stresses with a wind-dependant formulation of the drag coefficient proposed by Geernaert et al. (1986); that is,

$C_{D}^{s}=10^{-3}\left(0.43+0.097\left|U_{10}\right|\right)$

where $U_{10}$ is the wind speed at $10 \mathrm{~m}$ above ground. Conventional bulk formulae are used to derive local evaporation rate and residual surface heat flux owing to shortwave and longwave radiation plus sensible and latent heat fluxes. Turbulent exchange coefficients for latent and sensible heat are assumed to be functions of both wind speed and air-sea temperature differences (see Luyten et al., 1999). This implies that stability of the atmospheric boundary layer enters the bulk formulae as variable Dalton and Stanton numbers. For simplicity, we assume that solar radiation is absorbed within the upper layer of the model. The surface salt (freshwater) flux is a function of sea surface salinity, and the difference between evaporation and precipitation rates.

Coastlines and seabed are impermeable boundaries where normal fluxes of heat and salt vanish. A quadratic bottomdrag formula is used in which the drag coefficient is a function of the roughness length according to

$C_{D}^{b}=\left\{k / \ln \left(z_{r} / z_{o}\right)\right\}^{2}$,

where $z_{r}$ is a reference height taken at the grid centre of the bottom cell, $\kappa=0.4$ is van Karman's constant, and $z_{o}$ represents the bottom roughness length. The latter parameter has been chosen at $z_{o}=0.003 \mathrm{~m}$ following a number of tidal simulations. This gave reasonable agreement with previous tidal studies (e.g. Najafi, 1997).

River discharge is implemented in the model by means of inflow of a low-salinity (salinity is 20) surface layer of $1.5 \mathrm{~m}$ in thickness and $700 \mathrm{~m}$ in width. Riverine inflow is assumed to vary in a sinusoidal fashion with minimum values of $350 \mathrm{~m}^{3} / \mathrm{s}$ in October and a maximum of $650 \mathrm{~m}^{3} / \mathrm{s}$ in April. This gives an annual-mean river discharge of $500 \mathrm{~m}^{3} / \mathrm{s}$ $\left(15.8 \mathrm{~km}^{3} / \mathrm{yr}\right)$, which we deem a realistic estimate of current discharge rates. Tidal influences on this discharge are ignored. River temperatures are assumed to vary between minimum values of $16^{\circ} \mathrm{C}$ in December and peak values of $32^{\circ} \mathrm{C}$ in July.

Amplitudes and phases of the four major tidal constituents, M2, S2, O1, and K1, are prescribed as constant values along the eastern open-ocean boundary (Table 2). Co-amplitudes and co-phases (not shown) predicted for each of the above tidal constituents in the Persian Gulf differ by less than $10 \%$ compared with previous simulations (Landner et al., 1982; Le-Provost, 1984; El-Shabh and Murty, 1988; Bashir et al., 1989; Protor et al., 1994; Najafi, 1997). In the context of this work, we take this as an accurately enough representation of tides in the Persian Gulf. The reference sea level along the open-ocean boundary is kept constant over time.

At the open-ocean boundary we prescribe 2-layer profiles of temperature and salinity, derived from hydrographic observations (Alessi et al., 1999) on a monthly basis (Table 3). Temperature and salinity do only vary significantly in the upper $60 \mathrm{~m}$ of the water column. The water column underneath does not experience significant temporal variations and is kept at a temperature of $22^{\circ} \mathrm{C}$ and salinity of 36.5 throughout the simulations. Any inflow predicted by the model carries this boundary data into the model domain, whereas zerogradient conditions are employed for outflows. To avoid initial gravitational adjustment problems at this boundary, we 
Table 2. Tidal amplitudes and phases prescribed at the eastern boundary.

\begin{tabular}{llll}
\hline Tidal Constituent & Period (h) & Amplitude (m) & Phase (deg) \\
\hline Principal lunar semidiurnal $\mathrm{M}_{2}$ & 12.42 & 1.1 & 214.980 \\
Principal lunar diurnal $\mathrm{O}_{1}$ & 25.82 & 0.6326 & 192.200 \\
Principal solar semidiurnal $\mathrm{S}_{2}$ & 12.00 & 0.4416 & 248.900 \\
Lunisolar diurnal K & 23.93 & 0.3378 & 289.300 \\
\hline
\end{tabular}

Table 3. Monthly mean upper-ocean salinity and temperature $\left({ }^{\circ} \mathrm{C}\right)$ values prescribed at the eastern boundary.

\begin{tabular}{lllllllllllll}
\hline Months & J & F & M & A & M & J & J & A & S & O & N & D \\
\hline Salinity & 36.6 & 36.6 & 36.7 & 36.8 & 36.9 & 37.0 & 37.1 & 37 & 36.9 & 36.9 & 36.7 & 36.7 \\
Temperature & 19.5 & 21.0 & 23.2 & 25.6 & 27.1 & 28.6 & 29.9 & 30.9 & 28.1 & 25.7 & 24.9 & 20.1 \\
\hline
\end{tabular}

slowly adjust the boundary profiles from initially uniform values to real values over the first simulation year.

\subsection{Turbulence closure}

Turbulent viscosity is assumed to equal turbulent diffusivity. The horizontal turbulent exchange coefficient, $A_{h}$, is taken proportional to the product of lateral grid spacings, $\Delta x$ and $\Delta y$, and the sheared velocities, in analogy with Smagorinsky's (1963) parameterisation; that is,

$A_{h}=c \Delta x \Delta y D_{T}$,

where

$D_{T}^{2}=(\partial u / \partial x)^{2}+(\partial v / \partial y)^{2}+0.5(\partial u / \partial y+\partial v / \partial x)^{2}$,

where $u$ and $v$ are zonal and meridional flow components, and the parameter $c$ has been chosen at $c=0.2$ (Oey and Chen 1992). In our simulations, horizontal turbulent exchange coefficient attains typical values of $15 \mathrm{~m}^{2} / \mathrm{s}$ with peak local values in the Strait of Hormuz of $\sim 150 \mathrm{~m}^{2} / \mathrm{s}$. Vertical turbulence is parameterised by a level 2.5 turbulence closure of Mellor and Yamada (1982) with the modifications introduced by Galperin et al. (1988). This gave reasonably accurate predictions of the seasonal cycle of vertical stratifications of temperature and salinity in the Persian Gulf (see Sect. 3).

\subsection{Numerical implementations}

The model equations are discretised on an Arakawa C-grid (Arakawa and Suarez, 1983). A mode-splitting technique is employed to maximise model performance. A predictorcorrector method is used to solve the horizontal momentum equations. This satisfies the requirement that, when using a mode-splitting technique of solution, the currents in the three-dimensional equations should have the same depth integral as the ones obtained from the two-dimensional, depthintegrated equations (Blumberg and Mellor, 1987). The
TVD (Total Variation Diminishing) scheme using the superbee limiter as a weighting function between the upwind scheme and either the Lax-Wendroff scheme in the horizontal or the central scheme in the vertical is used to represent advection of scalars such as temperature and salinity. A simple upstream scheme is used for momentum advection. All horizontal derivatives are evaluated explicitly while vertical diffusion is computed fully implicitly and vertical advection quasi-implicitly. Forward-backward interpolation of the Coriolis term is implemented (Sielecki, 1968). In this application, we use time steps of barotropic and baroclinic modes of $10 \mathrm{~s}$ and $80 \mathrm{~s}$, respectively, which satisfy stability criteria associated with external and internal wave propagation, advection, and hydrostatic consistency (see Mesinger and Janjic, 1985). Data assimilation methods (other than prescription of boundary data) are not employed. Further details of numerical techniques employed in the COHERENS model can be taken from Luyten et al. (1999).

\subsection{Experimental design}

Total simulation times of experiments, run in a fully prognostic mode, are 20 years, which is sufficiently long for a steadystate seasonal cycle of circulation and water mass properties to develop in the Persian Gulf. Tidal boundary forcing is maintained throughout the simulations. Numerous case studies have been run in considerations of 1) variations of parameter values, 2) effects of enhanced river discharge and variations in atmospheric forcing, 3) variations in bathymetry, and 4) choices of different advection schemes and turbulence closures. These case studies were used for model validation and verification and form the basis of the simulation results presented below. This paper presents findings derived from the last 1-2 years of a selected 20-year simulation that gave reasonable agreement with observational evidence. Results presented below are fairly robust and do not change significantly 

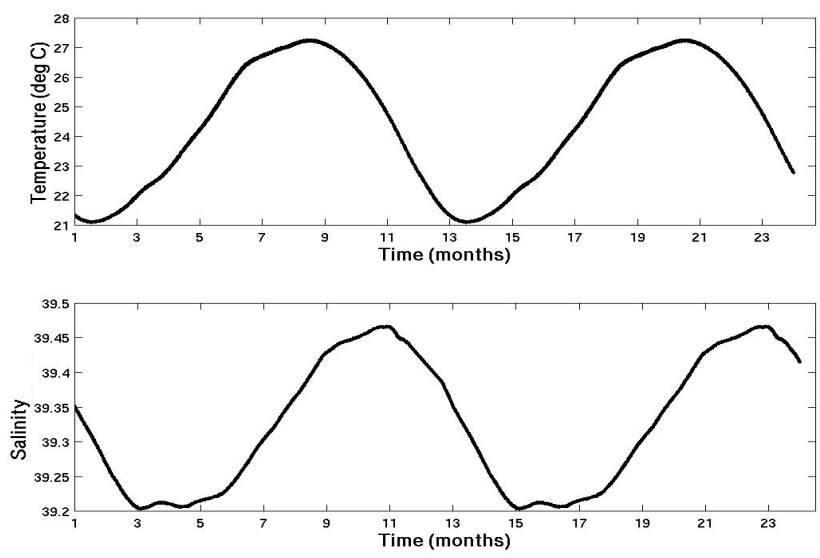

Fig. 2. Time series of domain-averaged temperature $\left({ }^{\circ} \mathrm{C}\right.$, top panel) and salinity (bottom panel) for the last two years of the 20 -year long simulation.

for variations of parameters (within reasonable range). An exception to this was the choice of the advection scheme for scalars (temperature and salinity). Highly diffusive advection schemes such as the upstream scheme produced an artificial, unwanted salinity trend in the Gulf of $\sim 1$ increase per year and were therefore discarded.

\section{Results and discussion}

\subsection{Annual cycle of temperature und salinity}

The predicted annual-mean surface-averaged evaporation rate is $1.8 \mathrm{~m} / \mathrm{yr}$, which is in agreement with previous estimates of Privett (1959), Hastenrath and Lamb (1979), Meshal and Hassan (1986), and Ahmad and Sultan (1990). The annual-mean, surface-averaged heat flux is $-4 \mathrm{~W} \mathrm{~m}^{-2}$, which agrees with the estimate of $-7 \pm 4 \mathrm{~W} \mathrm{~m}^{-2}$ by Johns et al. (2003). Gulf-averaged temperature and salinity attain a robust, steady seasonal cycle within 4-5 years of simulation time and onward (Fig. 2). Gulf-averaged temperature follows the seasonal cycle of incident solar radiation with a time lag of 1-2 months. Gulf-averaged salinity, on the other hand, attains minimum values during March-May each year. Effects of precipitation and river run-off on salinity changes are negligible on a gulf-wide scale. Therefore, decreases in salinity can be fully attributed to inflow of IOSW that, in agreement with observational evidence, peaks in spring. Maximum salinities occur during October-December where the evaporative surface salinity flux dominates over injection of low-salinity water through the Strait of Hormuz.

\subsection{Comparison with hydrographic field data}

From the model results we have constructed temperaturesalinity-season diagrams in different boxes along the Gulf for comparison with observational evidence (Alessi et al., 1999).

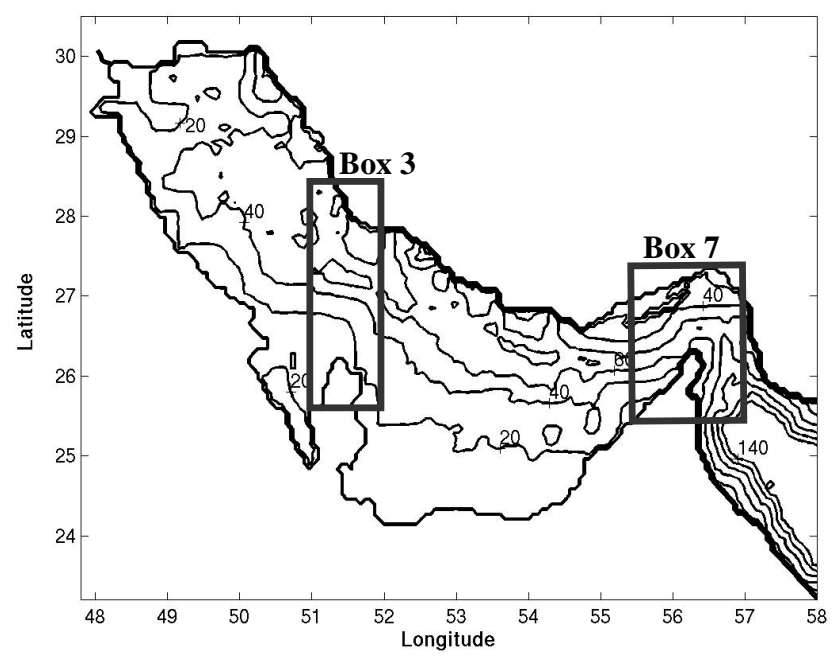

Fig. 3. Locations of boxes used for detailed analysis of hydrographic properties.

This was done for all boxes defined by Alessi et al. (1999). To keep this paper short, we only discuss outcomes for the central Gulf region (Box 3) and for the Strait of Hormuz (Box 7). Figure 3 shows the location of these boxes. Note that in contrast to Alessi et al. (1999) our Box 3 includes shallow regions around Bahrain.

\subsubsection{The Strait of Hormuz}

The Strait of Hormuz region is exposed to inflow of IOSW and outflow of saline bottom water formed in different areas of the Persian Gulf that will be identified further below.

In winter, we encounter a situation of weak temperature contrasts in the Strait waters of $<3^{\circ} \mathrm{C}$, but strong salinity differences of $\sim 4.5$ (Fig. 4). Modified IOSW appears with a temperature of $\sim 22^{\circ} \mathrm{C}$, a salinity of 36.5 , and a density of $1025.5 \mathrm{~kg} \mathrm{~m}^{-3}$. The dense outflow water attains a temperature of $\sim 22.5^{\circ} \mathrm{C}$, a salinity of 41 , and a density of $1028.5 \mathrm{~kg} \mathrm{~m}^{-3}$. Density in Strait waters ranges by $3 \mathrm{~kg} \mathrm{~m}^{-3}$. Note that temperature and salinity of the outflow are $\sim 1^{\circ} \mathrm{C}$ and $\sim 0.5$ too high as compared with field data (Johns et al., 2003).

In spring, we observe a significant change in water mass properties in the Strait region. Modified IOSW appears as a distinct thermally stratified (temperature range is $20-28^{\circ} \mathrm{C}$ ) and low-salinity (salinities are 36.5-37) water mass. Temperature of the densest bottom water decreases to $\sim 20^{\circ} \mathrm{C}$ as a remote effect of winter cooling of its source waters, so that the density of the bottom water increases to $>1029 \mathrm{~kg} \mathrm{~m}^{-3}$. Due to changes in both surface and bottom water mass properties, density contrasts in Strait waters increase to $6 \mathrm{~kg} \mathrm{~m}^{-3}$, which is mainly the effects of establishment of thermal stratification in the IOSW layer. This combination of inflow and outflow leads to a pronounced L-structure in the temperature-salinity diagram, also evident in the field data. 

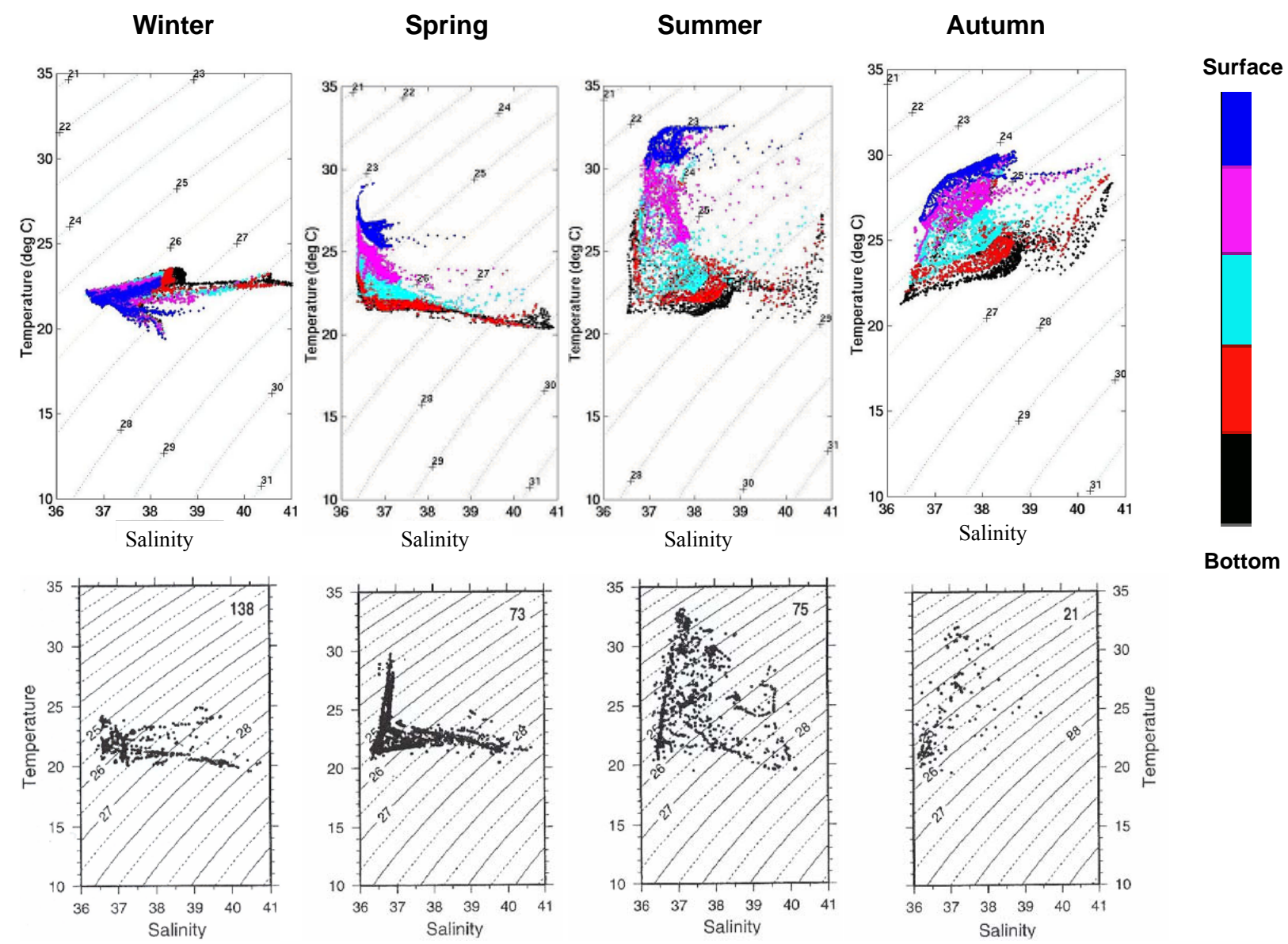

Bottom

Fig. 4. Temperature-salinity-season diagrams for the Strait of Hormuz. (top) Model predictions. Colours indicate sigma levels. (bottom) Field observations, taken from Alessi et al. (1999).

In summer, the salinity of the IOSW layer increases to $37-$ 38 , while the surface temperature increases to $>30^{\circ} \mathrm{C}$. The predicted salinity increase in surface water is associated with coverage of shallow regions off western Musandam Peninsula (see Fig. 1) where evaporation forms water of slightly elevated salinities. Top-to-bottom temperature gradients exceed $12^{\circ} \mathrm{C}$. We also find that intermediate water layers become saltier owing to diapycnal mixing. Interestingly, there is a warming of the most saline bottom waters by $\sim 5^{\circ} \mathrm{C} \mathrm{com-}$ pared with the situation in spring. This warming is also seen in the field data (SB2003).

In autumn, the IOSW source water has become colder (see Table 3) and intense lateral and vertical mixing occurs in the Strait (and elsewhere in the Gulf). Lateral mixing is provided by mesoscale eddies that start to form in this season (see below). Vertical mixing is associated with convective erosion of summer thermal stratification. As a result of this, the temperature of bottom water seen in the Strait increases to $\sim 22^{\circ} \mathrm{C}$ and the density of this water mass decreases to $1027.5 \mathrm{~kg} \mathrm{~m}^{-3}$. Density contrasts in the Strait decrease to $3.5 \mathrm{~kg} \mathrm{~m}^{-3}$. Owing to further cooling of the IOSW and con-

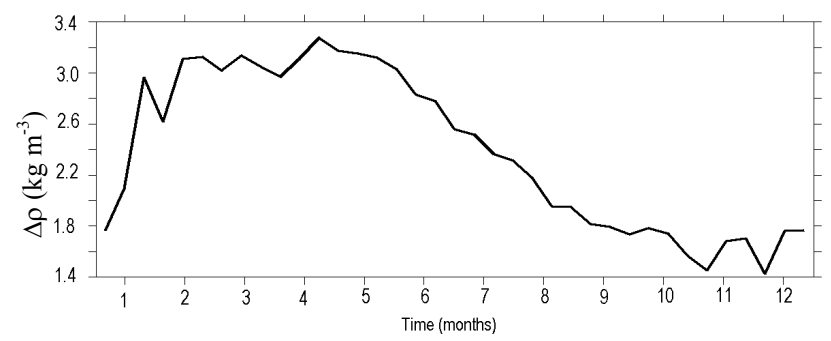

Fig. 5. Seasonal variations of the difference in densities at both sides of the Strait of Hormuz at a depth level of $\sim 70 \mathrm{~m}$.

vective stirring, the seasonal cycle is completed to lead to winter conditions of relatively weak temperature contrasts, but haline stratification remains. Note the overall good agreement between field measurements and model predictions.

The baroclinic exchange circulation through the Strait of Hormuz is modified by the difference between the density of Gulf Bottom Water west of the Strait of Hormuz and that of water at comparable depths outside the Gulf. In our 
Winter
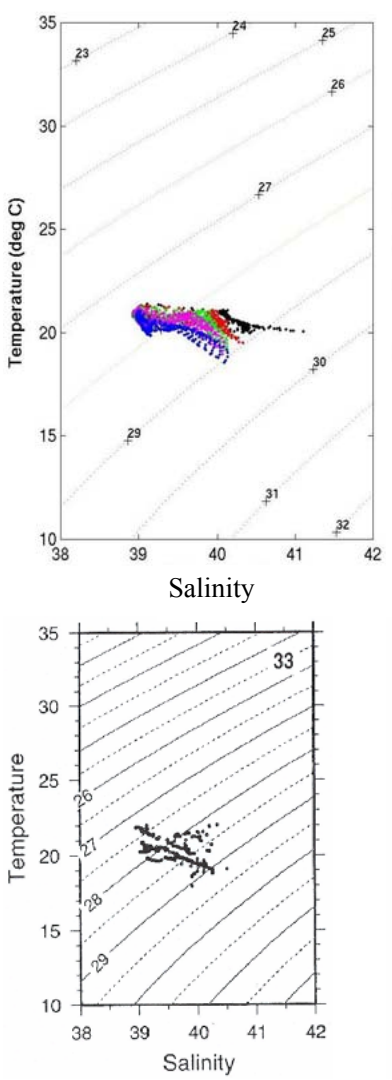

Spring
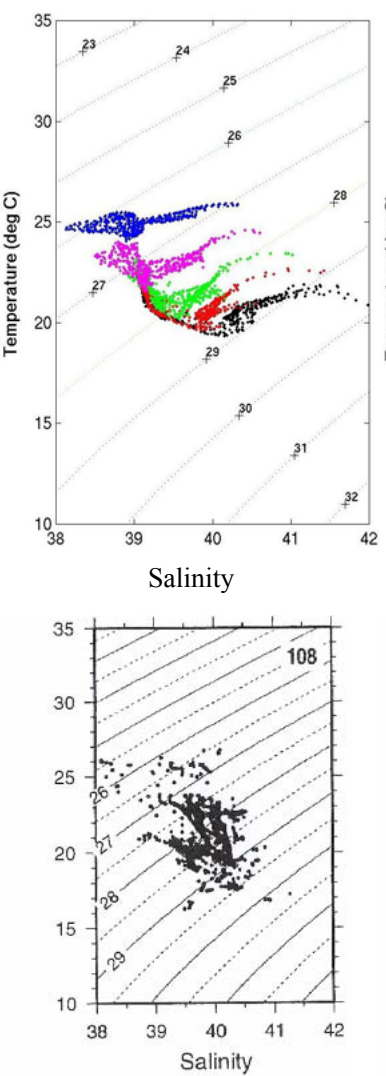

Summer
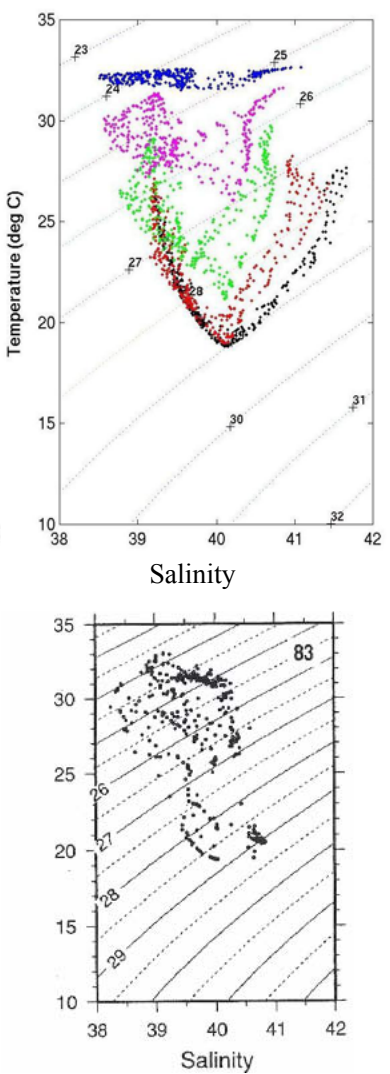

Autumn

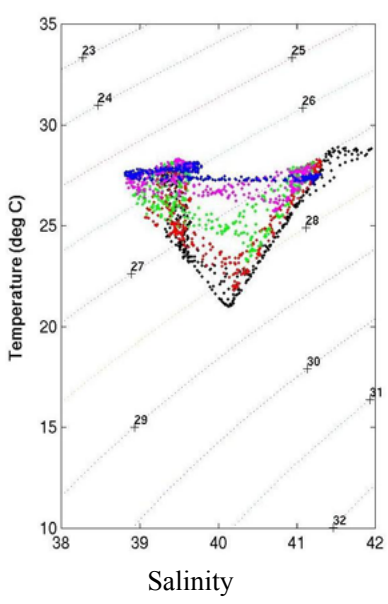

Bottom

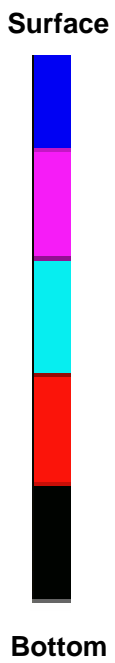

No data

Fig. 6. Same as Fig. 5, but for central regions of the Persian Gulf.

simulation, this density difference peaks during FebruaryMay (Fig. 5). It has an average value of $\sim 2.4 \mathrm{~kg} \mathrm{~m}^{-3}$ and varies by $\pm 40 \%$ over a year. In agreement with field observations (SB2003), the density difference attains little variations during February-May, whereas a significant change occurs from June to August associated with overall warming of Gulf bottom water. Simulated volume transports of this outflow vary between $\sim 0.17 \mathrm{~Sv}$ in spring and $\sim 0.11 \mathrm{~Sv}$ in autumn, which is close to values reported by Johns et al. (2003). Obviously, density contrasts across the Strait modify the strength of the outflow, in consistency with hydraulic theory (e.g. Pratt and Lundberg, 1991). Strengths of inflow and outflow are correlated to each other, so that the magnification of IOSW influx is driven by a stronger bottom outflow. This coupling can be explained by geostrophic adjustment theory (see Appendix).

\subsubsection{Central region of the Persian Gulf}

In winter, waters of the central region of the Persian Gulf (Box 3) exhibit only little spatial variations in temperature of $\sim 1{ }^{\circ} \mathrm{C}$ (Fig. 6). Temperature is $\sim 20^{\circ} \mathrm{C}$, which is $\sim 2^{\circ} \mathrm{C}$ cooler compared with Strait water. There is a pronounced vertical salinity stratification with top-to-bottom salinity gradients of $\sim 1$ and salinities span a range of 39-41, which includes lateral variations. Bottom water has a density of $1028.5-1029.5 \mathrm{~kg} \mathrm{~m}^{-3}$, which is slightly denser compared with bottom water found in the Strait (see Fig. 5).

In spring, local warming and import of warm $\left(\sim 25^{\circ} \mathrm{C}\right)$ modified IOSW leads to establishment of thermal stratification with top-to-bottom temperature differences of $6-7^{\circ} \mathrm{C}$. Surface water consists of modified IOSW that appears in this region with salinities in a range of 38-39, saline (values $>40$ ) waters forming in the shallow regions around Bahrain, and a water mass of salinities of 39-40 stemming from northwestern parts of the Gulf (see below). There is evidence of a water mass of temperatures of $19-20^{\circ} \mathrm{C}$, salinities of 40-41, and densities of $1028.8-1029 \mathrm{~kg} \mathrm{~m}^{-3}$, that SW2003 refer to as Gulf Deep Water. In agreement with SW2003, our simulation suggests that this water mass does only undergo slight variations in density over a year.

In summer, thermal stratification intensifies to vertical gradients of $>14^{\circ} \mathrm{C}$ with surface water warming up to $>32^{\circ} \mathrm{C}$. The salinity of modified IOSW increases by 0.5 . Saline 

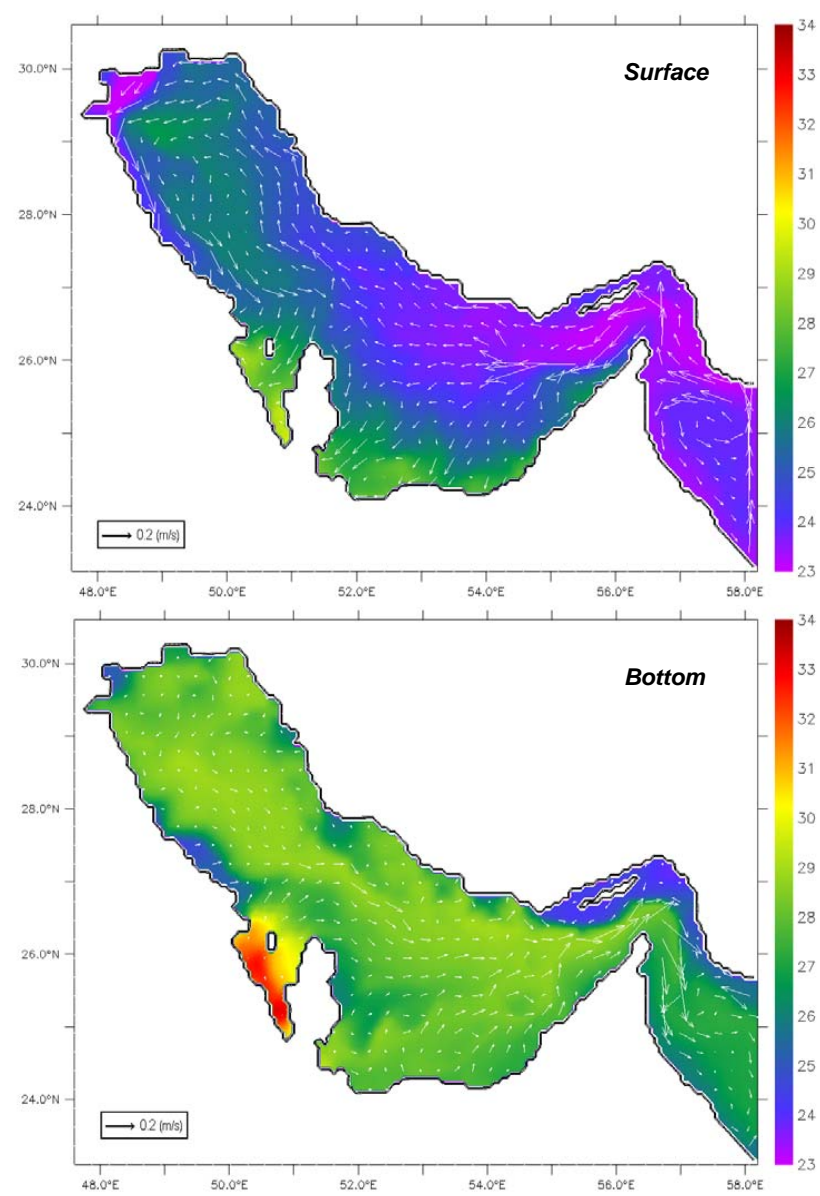

Fig. 7. Lateral distributions of surface and bottom flow vectors (arrows, $\mathrm{m} \mathrm{s}^{-1}$ ) over density (colours, sigma-t units) averaged over summer months (June-August). Flow vectors are averaged over $5 \times 5$ grid cells for visualisation purposes.

waters from shallow regions around Bahrain, not captured by the field data, become warmer throughout the water column.

In autumn, surface waters are cooled down to temperatures of $\sim 27^{\circ} \mathrm{C}$, while the salinity range remains similar to that observed during summer. Mixing occurs between three water masses. These are 1) low-salinity modified IOSW, 2) high-salinity water formed around Bahrain, and 3) Gulf Deep Water. Owing to mixing the latter becomes slightly warmer by $\sim 1{ }^{\circ} \mathrm{C}$ during autumn and its density increases slightly to $1028.4 \mathrm{~kg} \mathrm{~m}^{-3}$. River-derived surface water cannot be identified in the temperature-salinity-season diagrams for the central region of the Gulf.

\subsection{Seasonal variation of gulf-wide circulation}

The circulation in the Persian Gulf displays an interesting seasonal behaviour. By summer, a cyclonic overturning circulation establishes along the full length of the gulf (Fig. 7). Under the influence of the Coriolis force, the surface inflow
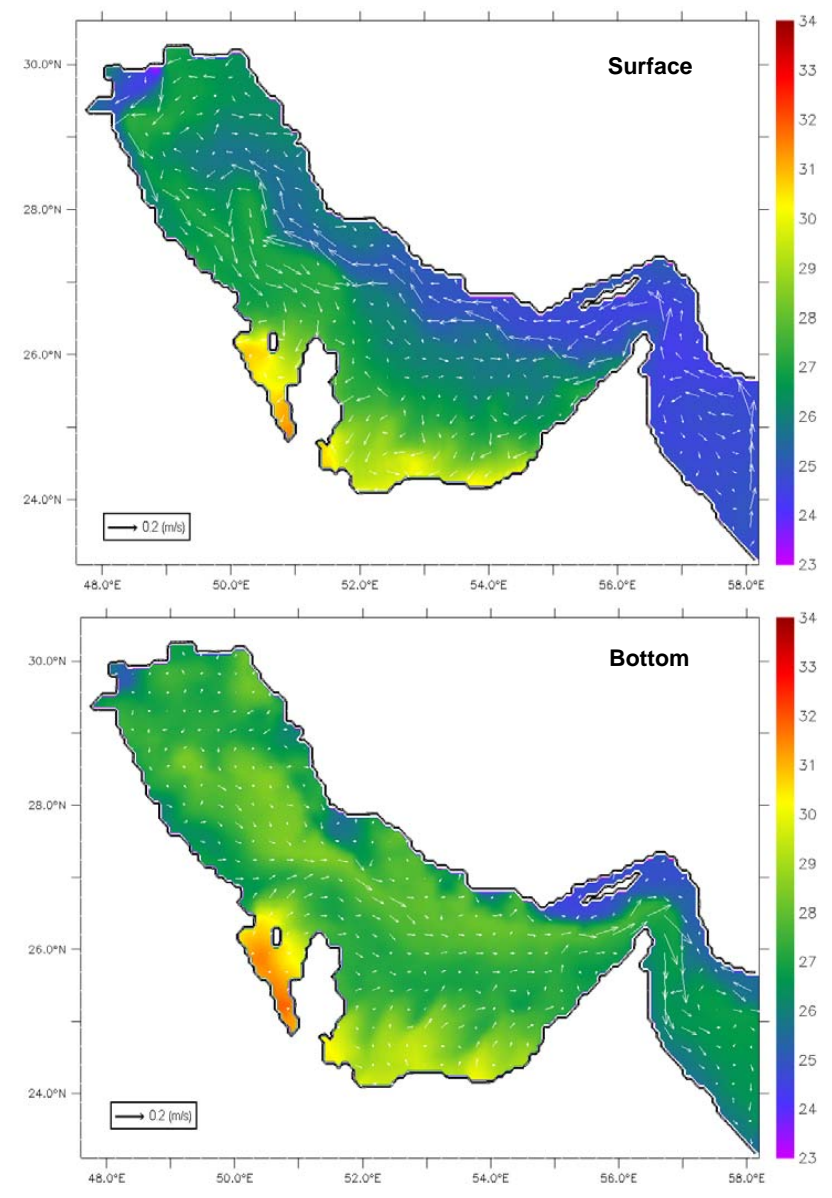

Fig. 8. Same as Fig. 7, but for autumn months (SeptemberNovember).

through the Strait of Hormuz leans against the Iranian coastline. This inflow (hereafter referred to as Iranian Coastal Jet or ICJ) has a pronounced bottom signature along the Iranian coast to a longitude of $55^{\circ} \mathrm{E}$, in agreement with longitudinal salinity transects presented by SB2003. To the west of this, the ICJ loses contact to the seafloor and turns into a buoyant surface flow. At the head of the Gulf, the ICJ joins the river plume fed by the Shatt-Al-Arab and flows back southeastward along the coasts of Kuwait and Saudi Arabia. River discharge leads to formation of a classical river plume of a width of $30-40 \mathrm{~km}$ that, in summer, flows around Qatar and reaches western parts of the Southern Shallows. Tidal stirring dissolves the river plume with ambient water along the coast of Saudi Arabia. Local tidal mixing zones are also evident along the Iranian coastline. Being surrounded by surface waters of lower salinity, a largely stagnant region establishes in the centre of the northwestern part of the Gulf, in agreement with Reynolds (1993), that displays slightly elevated densities, stemming from elevated salinities (see below). This region can be referred to as a salt plug (Wolanski, 

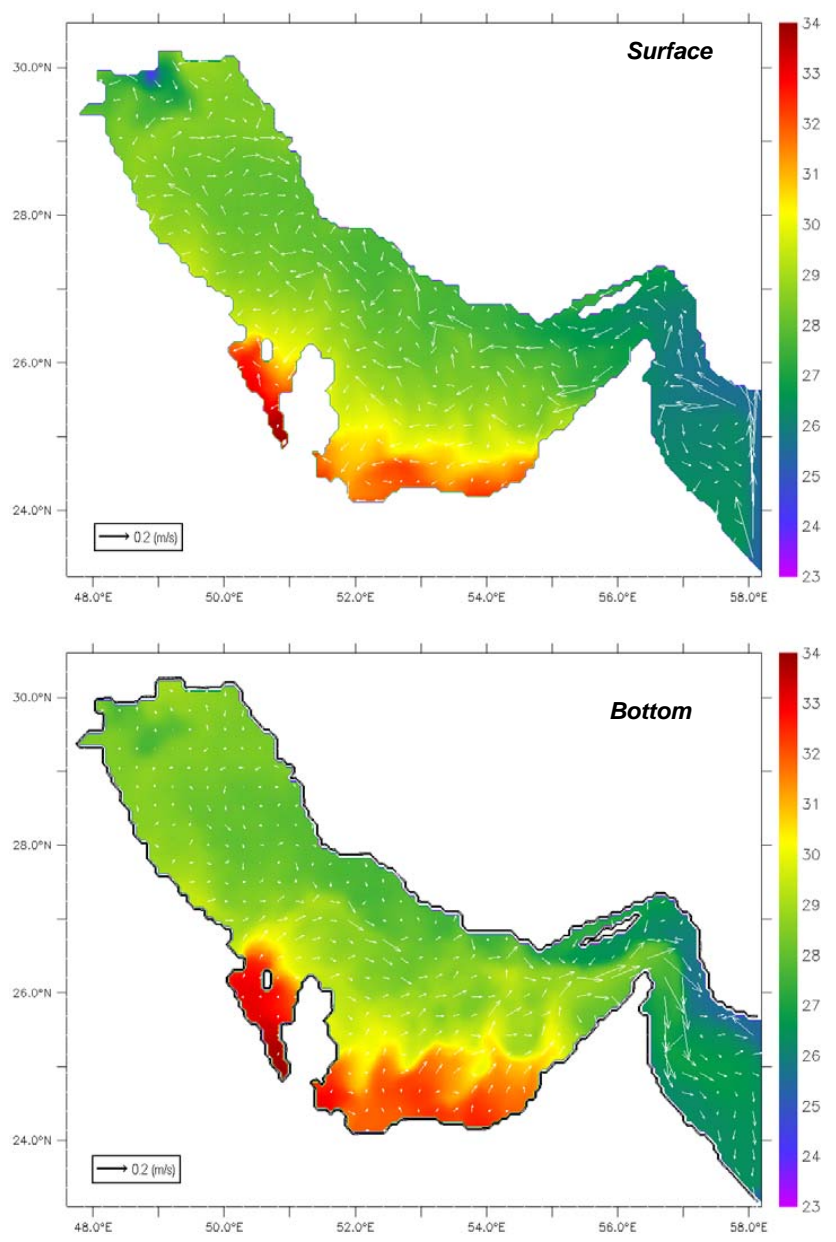

Fig. 9. Same as Fig. 7, but for winter months (December-February).

1986). Surface currents attain typical speeds of $10-20 \mathrm{~cm} / \mathrm{s}$. There are persistent south-westward surface currents in the southern regions of the Gulf away from Iran that turn into onshore (southward) flow in the Southern Shallows and near the shallows west of Qatar, in agreement with Hunter (1983). Summer densities in bottom layers are almost uniform, and dense bottom flow toward the Strait of Hormuz extends the entire length of the Gulf. The densest water is found in the shallows around Bahrain with values of $>1033 \mathrm{~kg} \mathrm{~m}^{-3}$. This water becomes partially diluted with low-salinity water provided by the river plume, but is seen to contribute to the dense bottom flow, in contrast to suggestions by SB2003. The bottom flow attains typical speeds of $5-10 \mathrm{~cm} / \mathrm{s}$, but magnifies to $20-30 \mathrm{~cm} / \mathrm{s}$ past the Strait of Hormuz, in agreement with ADCP data (Johns and Olson, 1998; Johns et al., 2003). Bottom waters in the Southern Shallows do not display elevated densities compared with ambient bottom waters and, therefore, do not significantly contribute to the driving of the dense bottom outflow in summer.

In autumn, where field data are lacking, the ICJ becomes dynamically unstable and forms meanders (Fig. 8). As a
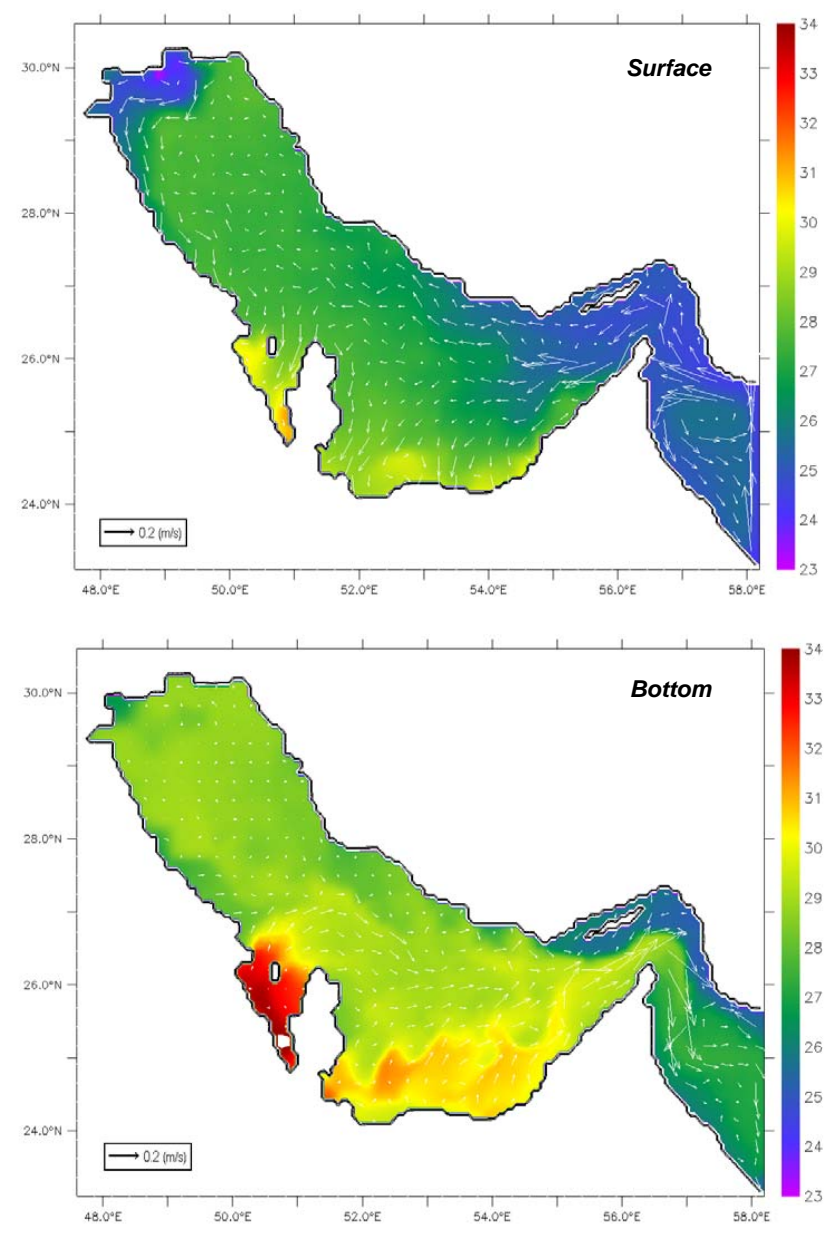

Fig. 10. Same as Fig. 7, but for spring months (March-May).

result of this, the ICJ detaches from the Iranian Coast at a longitude of $51^{\circ} \mathrm{E}$. Autumn cooling produces relatively denser bottom water in the Southern Shallows which starts to contribute to driving of the dense bottom flow. The density of this bottom water locally exceeds $1030 \mathrm{~kg} \mathrm{~m}^{-3}$ and mesoscale eddies form along a density front forming in the Southern Shallows along the 20-m depth contour. Dense water from the Southern Shallows becomes entrained into the dense bottom flow that still extends the full length of the Gulf.

In winter, the dynamically stable summer surface circulation has disintegrated into a concert of mesoscale eddies, confined to surface layers, that are evident throughout the Gulf (Fig. 9). The river plume has disappeared under the action of eddies mixing. Thus, the winter surface currents are spatially and temporarily highly variable. Eddies that attain diameters of 50-100 km, which is about fourfold the internal deformation radius. This indicates the presence of the baroclinic instability process (see Cushman-Roisin, 1996). Previous model simulations were void of mesoscale structures (see Chao et al., 1992), presumably due to too coarse lateral grid 

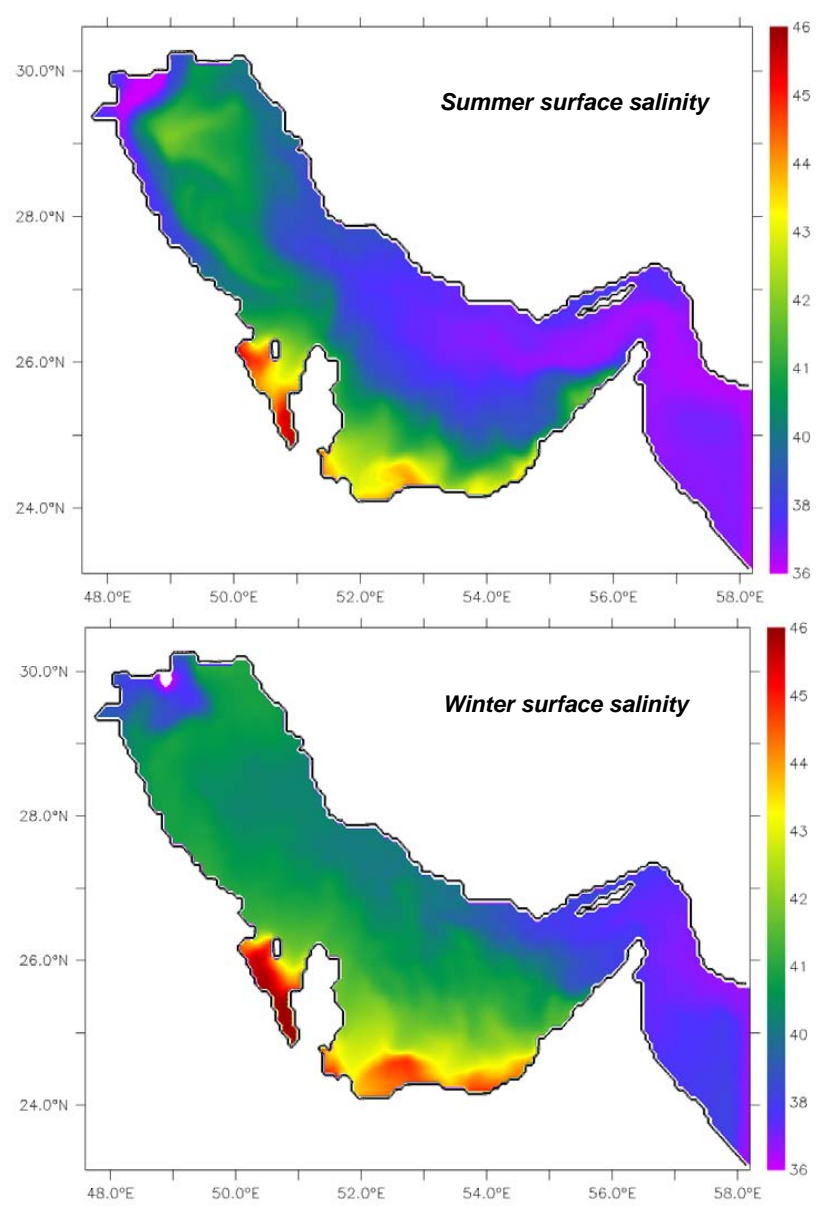

Fig. 11. Simulated surface salinities averaged over (top) summer months (June-August) and (bottom) winter months (DecemberFebruary).

spacing $(\sim 20 \mathrm{~km})$. Autumn and winter cooling has produced a very dense water mass in the Southern Shallows (density is $>1032 \mathrm{~kg} \mathrm{~m}^{-3}$ ) that now, with some minor contribution of dense water formed around Bahrain, dominates the driving of the dense bottom outflow toward the Strait of Hormuz. Formation of this extremely dense water is associated with the existence of extensive shallow areas in the Southern Shallows. Owing to advective delay, the result of this density increase is seen in the Strait of Hormuz in the period of January-May (see Fig. 4), so that there is a 3-month delay between the formation of anomalously dense water in the Southern Shallows and its appearance in the Strait. Note the injections of dense water from the Southern Shallows in form of narrow saline tongues inherent in mesoscale instabilities in the bottom layer. There is observational evidence of local lateral intrusion of saline, dense water stemming from the Southern Shallows (see Fig. 7a in SB2003). Deep flow in the north-western Gulf is largely absent in winter.

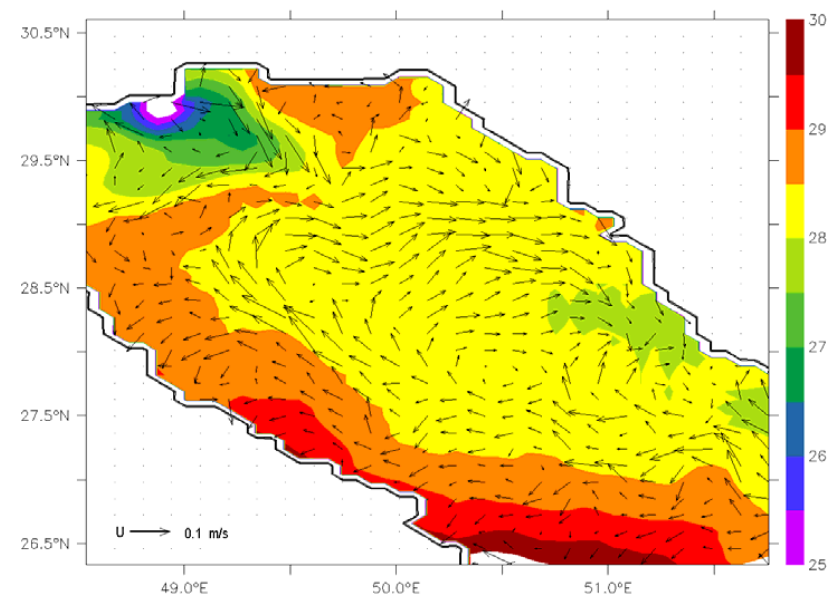

Fig. 12. Close-up of lateral distributions of surface flow vectors (arrows, $\mathrm{m} \mathrm{s}^{-1}$ ) over density (colours, sigma-t units) averaged over winter months (December-February). Spatial averaging has not been applied to flow vectors.

In spring, when density differences across the Strait of Hormuz are at maximum, the ICJ starts to form and moves toward the head of the Gulf, but also intrudes the Southern Shallows (Fig. 10), in agreement with observational evidence (Reynolds, 1993; SB2003). Re-establishment of the river plume can be seen, and mesoscale baroclinic eddies have largely disappeared. Due to surface warming, the density excess of waters in the Southern Shallows gradually diminishes, but still dominates the driving of the exchange circulation through the Strait. Bottom flows in the north-western Gulf are still negligibly weak.

The model simulations indicate that the winter/spring period is the period in which the inflow of IOSW into the gulf starts to strengthen. During this time the front is spatially and temporally highly variable (see Figs. 9 and 10), and its location is not static. This makes it difficult to compare the climatologic mean location of the front, predicted by the model, with snapshot transects taken in February, as shown by Brewer and Dyrseen (1985) and Swift and Bowers (2003). Further field data are required to understand the complex nature of frontal development during this period for validation of our model prediction, which might have biases of timing of this inflow and of the strength of lateral mixing incurred by mesoscale frontal instabilities.

On the basis of axial density sections, SB2003 argue that the densest water of $>1029.5 \mathrm{~kg} \mathrm{~m}^{-3}$ forms near the head of the Gulf and suggest that this density excess controls the density-driven circulation in the Persian Gulf. One major factor speaks against this hypothesis. North-south sections across the Gulf (Figs. 8a-b in SB2003) in winter show a sharp density increase toward the Southern Shallows where densities are $>1030 \mathrm{~kg} \mathrm{~m}^{-3}$, exceeding values observed near the head. More importantly, the associated north-south 
density gradients near the Southern Shallows establish over a short distance of $\sim 50 \mathrm{~km}$ and are thus 1 order of magnitude stronger than those forming along the entire length of the Gulf (see Figs. 7a and 8b in SB2003). Thus, it is primarily this strong baroclinic north-south pressure gradient along the Southern Shallows that creates a swift geostrophic frontal flow and not that along the Gulf as previously suggested by SB2003.

Along the axes of the Gulf, our model findings for winter and spring show a slight density decrease in bottom water of $\sim 0.5 \mathrm{~kg} \mathrm{~m}^{-3}$ from the head to the centre and a density increase by $\sim 1 \mathrm{~kg} \mathrm{~m}^{-3}$ from the centre toward the Strait of Hormuz (see Figs. 9 and 10). In comparison with field data (see Fig. 7 of SB2003), the model appears to slightly overestimate the density anomaly in the southern Gulf, which is associated with entrainment of hypersaline water from the Southern Shallows. This bias could be the result of too high evaporation rates in this area and/or too strong lateral turbulent mixing. Nevertheless, we deem this feature irrelevant because along-gulf pressure gradients are negligibly small compared with those establishing across the Gulf in vicinity of the Southern Shallows and therefore have only little effect on the dynamics.

\subsection{Why the Persian Gulf is saltiest in winter}

It has puzzled many generations of oceanographers that surface water of the Persian Gulf is, in general, saltier in winter than in summer, as also predicted with our model application (Fig. 11). Intensification of the IOSW inflow in spring is a major reason why salinity in surface water along the Iranian coastline appears to be relatively low in summer. Establishment of thermal stratification supports this process. In autumn and winter, together with a weakening of the IOSW inflow, the low-salinity surface signature partially disappears under the effects of lateral stirring of mesoscale eddies and convective deepening of the surface mixed layer. Previous suggestions for interannual salinity variations in surface water of the Persian Gulf include seasonal changes of 1) river discharge (Schott, 1908), 2) wind stress (Chao et al., 1992), 3) evaporation (Emery, 1956), and 4) evaporative lowering of sea surface height in the Gulf (SB2003). Findings of sensitivity studies (not shown) indicate that neither of these factors have a significant impact on the seasonal cycle of circulation and water mass properties in the Persian Gulf. Instead of this, our simulations indicate that this seasonal cycle is associated with formation of dense bottom water in the Southern Shallows in autumn and winter (appearing in the Strait in late winter and spring) in conjunction with establishment of thermal stratification in spring. The formation of dense bottom water is due to surface cooling of extremely saline waters.

\subsection{Circulation in the northern Gulf}

During autumn and winter, our simulations indicate the establishment of a persistent clockwise circulation pattern in the northern Gulf (Fig. 12) including a persistent southeastward coastal jet along the Iranian coast with speeds of up to $10 \mathrm{~cm} / \mathrm{s}$. Existence of this coastal jet, forming during autumn (see Fig. 8), is in agreement with observational evidence (Reynolds 1993). During spring and summer this coastal jet is absent in the model simulation (see Figs. 7 and 10). Instead of this, the ICJ takes over to extend along the entire Iranian coastline. The summer circulation map, suggested by Reynolds (1993), could be biased by the occurrence of a transient upwelling event during the time of the measurements, which is difficult to verify in the lack of suitable meteorologic data. However, other evidences and, in particular, the effect on sediment transport (Uchupi et al., 1996) suggests that the formation of this coastal jet is, at least, recurrent. It should be kept in mind that our model is driven by monthly mean atmospheric forcing, which excludes the description of synoptic-scale upwelling events and effects caused by strong diurnal winds associated with sea breezes over the Gulf. These features might lead to establishment of a quasi-permanent coastal jet in summer, absent in our simulations.

\section{Conclusions}

Findings presented in this paper and summarised in the following provide new insight into seasonal variations of the circulation and water mass properties in the Persian Gulf. Our results, which are in good agreement with previous hydrographical data, suggest the following.

The densest water in the Persian Gulf forms during winter in shallow waters along the coast of United Arab Emirates (Southern Shallows) and around Bahrain. This is associated with atmospheric cooling of extremely saline water masses in shallow water. Overall, the evaporative salinity increase throughout the Gulf leads to a steady component of dense water outflow through the Strait of Hormuz. In summer and autumn, the bottom outflow extends the entire length of the Gulf. Dense water formed in the Southern Shallows strengthens the bottom outflow through the Strait of Hormuz during February-May. The lateral density difference driving this outflow varies seasonally by $\pm 40 \%$. In winter and spring, the bottom outflow regime is confined to the eastern portion of the Gulf with a minor contribution of dense waters forming around Bahrain. Intensified bottom outflow magnifies the influx of Indian Ocean Surface Water (IOSW) into the Gulf leading to the formation of the Iranian Coastal Jet (ICJ). Assisted by thermal stratification, the ICJ approaches the head of the Gulf by summer, by which a dynamically stable cyclonic gulf-wide overturning circulation has been established. This circulation becomes dynamically unstable in 
autumn and winter and breaks up into mesoscale eddies, so that the ICJ disappears. Lateral mixing by eddies and vertical mixing due to convective removal of the summer thermal stratification contributes to the fact that surface Gulf waters appear more saline in autumn and winter compared with spring and summer. Dense water formed around Bahrain only marginally contributes to the driving of the deep flow owing to dilution with river-derived low-salinity water and small volume compared to the Southern Shallows.

To further improve understanding of the circulation including seasonal variations in the Persian Gulf, more field observations are required to close data gaps that exist for autumn months for the entire Gulf and year-round for the Southern Shallows. Also required is a better knowledge of current river discharge rates of the Shatt-al-Arab.

Future theoretical studies should investigate effects of both varied river discharge and synoptic-scale wind and heat-flux forcing on the circulation in the Persian Gulf. The focus hereby should be placed into investigation of 1) heat fluxes and dense water formation in the Southern Shallows and 2) atmospheric conditions that promote formation of a coastal jet along the Iranian coast in the northern Gulf, not adequately described in our model simulations, and how this interacts with the gulf-wide circulation.

\section{Appendix A}

\section{Simple dynamical model of frontal flow through a strait}

Simple geostrophic adjustment theory for a two-layer frontal flow is considered to explain the coupling between magnitudes of inflow and outflow through the Strait of Hormuz. To this end, we consider the initial configuration of a wall of dense water of height $h_{0}$ with a density anomaly of $\Delta \rho$ leaning against the right-hand bank of a Strait of depth $H$ (Fig. A1).

The steady-state dynamical equations suitable to tackle this problem are the geostrophic equations and conservation of potential vorticity (see Cushman-Roisin, 1994). The geostrophic relations (see Fig. A1) are given by:

$$
\begin{aligned}
& f v_{1}=g \frac{\partial \eta}{\partial x} \\
& f v_{2}=\frac{\rho_{1}}{\rho_{2}} g \frac{\partial \eta}{\partial x}-g^{\prime} \frac{\partial h}{\partial x} \approx g \frac{\partial \eta}{\partial x}-g^{\prime} \frac{\partial h}{\partial x},
\end{aligned}
$$

where indices 1 and 2 refer to the upper and lower layer, respectively, $\eta$ is the resultant sea surface elevation, and $g^{\prime}=\left(\rho_{2}-\rho_{1}\right) / \rho_{2} g$ is reduced gravity. Note that the Boussinesq approximation $\left(\rho_{2} / \rho_{1} \approx 1\right)$ is used in Eq. (A2). Conservation of potential vorticity requires

$$
\frac{f+\partial v_{1} / \partial x}{h_{1}+h}=\frac{f}{h_{1}} \Rightarrow \frac{\partial v_{1}}{\partial x}=\frac{f}{h_{1}} h
$$
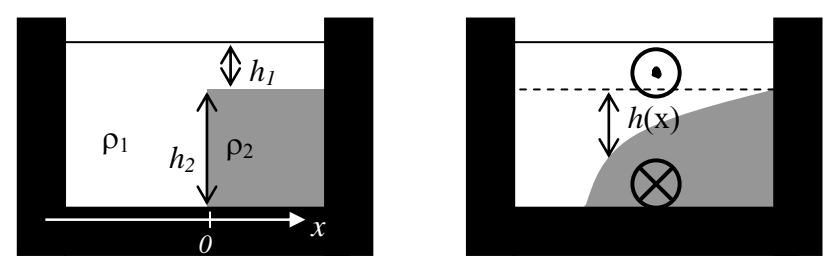

Fig. A1. Schematic of geostrophic adjustment of a two-layer density front in a Strait. (a) Initial configuration. (b) Baroclinic frontal flow and return flow in the upper ocean.

$\frac{f+\partial v_{2} / \partial x}{h_{2}-h}=\frac{f}{h_{2}} \Rightarrow \frac{\partial v_{2}}{\partial x}=-\frac{f}{h_{2}} h$,

where small changes in total water depth owing to sea level variations have been ignored; that is, the rigid-lid approximation has been employed. A combination of the latter Eqs. (A1-A4) gives:

$\frac{\partial^{2} h}{\partial x^{2}}=\frac{f^{2}}{g^{\prime} H} h$

with the equivalent depth being defined as $H=h_{1} h_{2} /\left(h_{1}+h_{2}\right)$. The solution of Eq. (A5) is:

$h(x)=\left\{\begin{array}{cc}h_{2} \exp [-(x+R) / R] ; & ; x \geq-R \\ h_{2} & ; x<-R\end{array}\right.$

where the internal deformation radius is given by $R=\sqrt{ }\left[\left(g^{\prime} H\right)\right] / f$. From Eqs. (A3) and (A4), we yield:

$v_{2}(x)=\left\{\begin{array}{cc}\sqrt{g^{\prime} H} \exp [-(x+R) / R] & ; x \geq-R \\ 0 \quad & x<-R\end{array}\right.$

$v_{1}(x)=-\frac{h_{2}}{h_{1}} v_{2}$.

Furthermore, inserting Eq. (A8) in (A1) gives the resultant sea level elevation:

$\eta(x)=\left\{\begin{array}{cc}-\eta_{0}\{1-\exp [-(x+R) / R]\} & ; x \geq-R \\ 0 & ; x<-R\end{array} ;\right.$

where $\eta_{0}=\left(\rho_{2}-\rho_{1}\right) / \rho_{2} h_{2}^{2} /\left(h_{1}+h_{2}\right)$. According to the above solutions, volume transports in the upper and lower layer can be calculated as:

$$
\begin{aligned}
Q_{2} & =\int_{-R}^{\infty} v_{2}\left(h_{2}-h\right) d x=0.5 \sqrt{g^{\prime} H} h_{2} R, \\
Q_{1} & =\int_{-R}^{\infty} v_{1}\left(h_{1}+h\right) d x \\
& =-\sqrt{g^{\prime} H} h_{2} R\left(1+0.5 h_{2} / h_{1}\right) \\
& =-2 Q_{2}\left(1+0.5 h_{2} / h_{1}\right) .
\end{aligned}
$$


The two latter equations suggest that, in the absence of other processes, the magnitude of the inflow would always exceed that in the lower layer by a factor $>2$. This implies that in a semi-enclosed estuary, such as the Persian Gulf, and for comparatively small evaporative losses, the sea level in the estuary would increase over time creating a barotropic pressure gradient along the Strait. This pressure gradient, in turn, would create an additional barotropic flow component through the Strait such that inflow and outflow attain volume transports of the same order of magnitude. The resultant steady-state volume transports can be derived as the average of magnitudes of Eqs. (A10) and (A11), yielding:

$$
\begin{aligned}
& Q_{2} \approx 0.5 \sqrt{g^{\prime} H} h_{2} R\left(1.5+0.5 h_{2} / h_{1}\right), \\
& Q_{1}=-Q_{2} .
\end{aligned}
$$

For parameters characterizing the exchange flow through the Strait of Hormuz $\left(\sqrt{\left(g^{\prime} H\right)} \approx 0.5 \mathrm{~m} / \mathrm{s}, \quad h_{2} \approx 40 \mathrm{~m}, \quad R \approx 7.7 \mathrm{~km}, \quad h_{2} / h_{1} \approx 1\right)$, Eq. (A12) yields an estimate of the volume transport of the outflow of $Q_{2} \approx 0.15 \mathrm{~Sv}$, with the inflow carrying approximately the same amount of water, which is of the order of magnitude as estimated by Johns et al. (2003). The overall essence of this consideration is that geostrophic adjustment of a density front in a Strait triggers a return flow in upper layers of the water column of a magnitude being correlated with that of the frontal outflow current.

Acknowledgements. This work was supported by an international postgraduate scholarship awarded by Khorramshahr University of Marine Sciences \& Technology, Iran, and a grant from Flinders University, South Australia. We thank SAPAC (South Australian Partnership of Advanced Computing) for provision of their facilities and for technical support. We are grateful to M. Tomczak and the referees for helpful suggestions that improved this paper.

Edited by: E. J. M. Delhez

\section{References}

Ahmad, F. and Sultan, S. A. R.: Annual mean surface heat fluxes in the Arabian Gulf and the net heat transport through the Strait of Hormuz, Atmos. Ocean., 29, 54-61, 1991.

Alessi, C. A., Hunt, H. D., and Bower, A. S.: Hydrographic data from the U.S. Naval Oceanographic Office: Persian Gulf, Southern Red Sea, and Arabian Sea 1923-1996, Woods Hole Oceanog. Inst. Tech. Rep., WHOI-99-02, 1999.

Arakawa, A. and Suarez, M. J.: Vertical differencing of the primitive equations in sigma coordinates, Mon. Wea. Rev., 111, 34-45, 1983.

Bashir, M., Khaliq, A. Q. M., and Al-Hawaj, A. Y.: An explicit finite difference, model for tidal flows in the Arabian Gulf, in: Computational techniques and applications: CTAC-89, edited by: Hogarth, W. L. and Noye, B. J., Griffith University, Brisbane, Queensland, Australia, Hemisphere Publishing Corp., New York, 295-302, 1989.
Blumberg, A. F. and Mellor, G. L.: A description of a three-dimensional coastal ocean circulation model, in: Threedimensional Coastal Ocean Models, edited by: Heaps, N. S., Coastal and Estuarine Sciences, vol. 4, American Geophysical Union, Washington D.C., 1-16, 1987.

Brewer, P. G. and Dyrssen, D.: Chemical Oceanography of the Persian Gulf, Prog. Oceanog., 14, 41-55, 1985.

Chao, S.-Y., Kao, T. W., and Al-Hajri, K. R.: A numerical investigation of circulation in the Arabian Gulf, J. Geophys. Res., 97, 11219-11 236, 1992.

Cushman-Roisin, B.: Introduction to Geophysical Fluid Dynamics, Prentice-Hall, Englewood Cliffs, N. J., 1994.

El-Shabh, M. I. and Murty, T. S.: Simulation of the movement and dispersion of oil slicks in the Arabian Gulf, Nat. Hazards, 1, 197219, 1988.

Emery, K. O.: Sediments and water of the Persian Gulf, AAPG Bull., 40, 2354-2383, 1956.

Galperin, B., Kantha, L. H., Hassid, S., and Rosati, A.: A quasiequilibrium turbulent energy model for geophysical flows, J. Atmos. Sci., 45, 55-62, 1988.

Geernaert, G. L., Katsaros, K. B., and Richter, K.: Variation of the drag coefficient and its dependence on sea state, J. Geophys. Res., 91, 7667-7679, 1986.

Hastenrath, S. and Lamb, P. J.: Climatic atlas of the Indian Ocean, Part 2, The ocean heat budget, Univ. of Wisc. Press, Madison, Wisconsin, 1979.

Hunter, J. R.: The physical oceanography of the Arabian Gulfs: a review and theoretical interpretation of previous observations, Marine Environment and Pollution, Proceedings of the First Arabian Gulf Conference on Environment and Pollution, Kuwait, 7 9 February 1982, 1-23. 1982.

Hunter, J. R.: Aspects of the dynamics of the residual circulation of the Arabian Gulf, in: Coastal oceanography, edited by: Gade, H. G., Edwards, A., and Svendsen, H., Plenum Press, 31-42, 1983.

Johns, W. E. and Olson, D. B.: Observations of seasonal exchange through the Strait of Hormuz, Oceanography, 11, 58, 1998.

Johns, W. E., Yao, F., Olson, D. B., Josey, S. A., Grist, J. P., and Smeed, D. A.: Observations of seasonal exchange through the Straits of Hormuz and the inferred freshwater budgets of the Persian Gulf, J. Geophys. Res., 108(C12), 3391, doi:10.1029/2003JC001881, 2003.

Landner, R. W., Belen, M. S., and Cekirge, H. M.: Finite difference model for tidal flows in the Arabian Gulf, Computers and Mathematics with Applications, 8(6), 425-444, 1982.

Le-Provost, C.: Models for tides in the KAP region, in: Oceanographic modelling of the Kuwait Action Plan (KAP) region, edited by: El-Sabh, M. I., UNESCO Rep. in Marine Science, 28, 37-45, 1984.

Luyten, P. J., Jones, J. E., Proctor, R., Tabor, A., Tett, P., and WildAllen, K.: COHERENS - A coupled hydrodynamical-ecological model for regional and shelf seas: user documentation, MUMM Rep., Management Unit of the Mathematical Models of the North Sea, 1999.

Mellor, G. L. and Yamada, T.: Development of a turbulence closure model for geophysical fluid problems, Rev. Geophys. Space Phys., 20, 851-875, 1982.

Meshal, A. H. and Hassan, H. M.: Evaporation from the coastal waters of the central part of the Gulf, Arabian Gulf Sci. Res., 4, 649-655, 1986. 
Mesinger, F. and Janji, Z. I.: Problems and numerical methods of the incorporation of mountains in atmospheric models, Lectures in Applied Mathematics, 22, 81-121, 1985.

Najafi, H. S.: Modelling tides in the Persian Gulf using dynamic nesting, $\mathrm{PhD}$ thesis, University of Adelaide, Adelaide, South Australia, 1997.

Oey, L.-Y. and Chen, P.: A model simulation of circulation in the Northeast Atlantic shelves and seas, J. Geophys. Res., 97, 20 087-20 115, 1992.

Perrone, T. J.: Winter shamal in the Persian Gulf, Tech. Rep., Naval Environ. Predict. Res. Facil., Monterey, Calif., 79-06, 1979.

Pratt, L. J. and Lundberg, P. A.: Hydraulics of rotating strait and sill flows, Annual Review of Fluid Mechanics, 23, 81-106, 1991.

Privett, D. W.: Monthly charts of evaporation from the North Indian Ocean, including the Red Sea and the Persian Gulf, Quart. J. Roy. Meteorol. Soc., 85, 424-428, 1959.

Proctor, R., Eliott, A., and Flather, R. A.: Modelling tides and surface drift in the Arabian Gulf-Application to the Gulf oil spill, Cont. Shelf Res., 14, 531-545, 1994.

Reynolds, R. M.: Physical oceanography of the Gulf, Strait of Hormuz, and the Gulf of Oman - Results from the Mt Mitchell expedition, Mar. Pollution Bull., 27, 35-59, 1993.

Saad, M. A. H.: Seasonal variations of some physiochemical condition of Shatt-al-Arab estuary, Iraq, Estuarine Coastal Mar. Sci., 6, 503-513, 1978.

Sadrinasab, M. and Kämpf, J.: Three-dimensional flushing times in the Persian Gulf, Geophys. Res. Letters, 31, L24301, doi:10.1029/2004GL020425, 2004.
Schott, G.: Oceanographie and Klimatologie des Persischen Golfes und des Golfes von Oman, Ann. Hydrogr. Mar. Meteorol., 46, 1-46, 1918.

Seibold, E. and Ulrich, J.: Zur Bodengestalt des nordwestlichen Golfs von Oman. "Meteor" Forsch. Ergebnisses, Reihe C, 3, 114, 1970.

Sielecki, A.: An energy-conserving finite difference scheme for the storm surge equations, Mon. Wea. Rev., 96, 150-156, 1968.

Smagorinsky, J.: General circulation experiments with the primitive equations. The basic experiment, Mon. Wea. Rev., 91, 99-165, 1963.

Sugden, W.: The hydrology of the Persian Gulf and its significance in respect to evaporite deposition, Amer. J. Sci., 261, 741-755, 1963.

Swift, S. A. and Bower, A. S.: Formation and circulation of dense water in the Persian/Arabian Gulf, J. Geophys. Res., 108(C1), 3004, doi:10.1029/2002JC001360, 2003.

UNESCO: Tenth report of the joint panel on oceanographic tables and standards, UNESCO Tech. Pap. in Marine Sci., No. 36, UNESCO, Paris, 1981.

Uchupi, E., Swift, S. A., and Ross, D. A.: Gas venting and late quaternary sedimentation in the Persian (Arabian) Gulf. Marine Geology, 129, 237-269, 1996.

Wolanski, E.: An evaporation-driven salinity maximum zone in Australian tropical estuaries, Estuarine, Coastal and Shelf Science, 22, 415-424, 1986.

Wright, J. L.: A hydrographic and acoustic survey of the Persian Gulf, MSc Thesis, Nav. Postgrad. Sch., Monterey, Calif., 1974. 